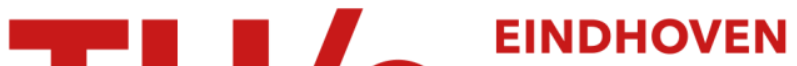 UNIVERSITY OF TECHNOLOGY
}

\section{Low-mach algorithm for heated droplet-laden turbulent channel flow including phase transition}

\section{Citation for published version (APA):}

Bukhvostova, A., Kuerten, J. G. M., \& Geurts, B. J. (2013). Low-mach algorithm for heated droplet-laden turbulent channel flow including phase transition. In T. Simos, G. Psihoyios, \& C. Tsitouras (Eds.), 11th International Conference of Numerical Analysis and Applied Mathematics (ICNAAM 2013) : Rhodes, Greece, September 21-27, 2013 (pp. 1083-1086). (AlP Conference Proceedings; Vol. 1558).

https://doi.org/10.1063/1.4825694

DOI:

$10.1063 / 1.4825694$

Document status and date:

Published: 01/01/2013

\section{Document Version:}

Publisher's PDF, also known as Version of Record (includes final page, issue and volume numbers)

\section{Please check the document version of this publication:}

- A submitted manuscript is the version of the article upon submission and before peer-review. There can be important differences between the submitted version and the official published version of record. People interested in the research are advised to contact the author for the final version of the publication, or visit the $\mathrm{DOI}$ to the publisher's website.

- The final author version and the galley proof are versions of the publication after peer review.

- The final published version features the final layout of the paper including the volume, issue and page numbers.

Link to publication

\section{General rights}

Copyright and moral rights for the publications made accessible in the public portal are retained by the authors and/or other copyright owners and it is a condition of accessing publications that users recognise and abide by the legal requirements associated with these rights.

- Users may download and print one copy of any publication from the public portal for the purpose of private study or research.

- You may not further distribute the material or use it for any profit-making activity or commercial gain

- You may freely distribute the URL identifying the publication in the public portal.

If the publication is distributed under the terms of Article 25fa of the Dutch Copyright Act, indicated by the "Taverne" license above, please follow below link for the End User Agreement:

www.tue.nl/taverne

Take down policy

If you believe that this document breaches copyright please contact us at:

openaccess@tue.nl

providing details and we will investigate your claim. 
Low-mach algorithm for heated droplet-laden turbulent channel flow including phase transition

A. BukhvostovaJ. G. M. KuertenB. J. Geurts

Citation: AIP Conference Proceedings 1558, 1083 (2013); doi: 10.1063/1.4825694

View online: http://dx.doi.org/10.1063/1.4825694

View Table of Contents: http://aip.scitation.org/toc/apc/1558/1

Published by the American Institute of Physics 


\title{
Low-Mach Algorithm for Heated Droplet-laden Turbulent Channel Flow Including Phase Transition
}

\author{
A.Bukhvostova*, J.G.M. Kuerten ${ }^{\dagger, *}$ and B.J. Geurts ${ }^{*, * *}$ \\ *Faculty EEMCS, University of Twente, Enschede, The Netherlands \\ ${ }^{\dagger}$ Department of Mechanical Engineering, Eindhoven University of Technology, Eindhoven, The Netherlands \\ ${ }^{* *}$ Department of Technical Physics, Eindhoven University of Technology, Eindhoven, The Netherlands
}

\begin{abstract}
In this contribution a turbulent channel flow with dispersed droplets is investigated. The dispersed phase undergoes phase transition, which leads to heat and mass transfer between the phases, and correspondingly modulates turbulent flow properties. As a point of reference we investigate the flow of water droplets in air, containing also water vapor. A full simulation was done using a time-explicit numerical model applying second order accurate finite volume discretization. However, simulation at realistic Mach numbers becomes very time consuming with the explicit method. A new low Mach number algorithm is proposed to simulate turbulent multiphase flow efficiently at realistic conditions. The explicit code is used as a point of reference for the results obtained with the new algorithm.
\end{abstract}

Keywords: droplets, two-phase flow, phase transition, low-mach flow, turbulent channel flow PACS: $47.27 \mathrm{E}-$

\section{INTRODUCTION}

Multiphase flows in which a large number of small droplets are dispersed in a gas, play an important role in a variety of technological applications. At sufficiently high mass and volume fraction the presence of the dispersed droplet phase directly modulates the flow through the exchange of momentum with the gas and with other droplets [1]. Dispersed multiphase flows not only exhibit this dynamic turbulence modulation, but may in addition show effects arising from phase transition. Turbulent spray cooling is a prime example in which the effect of phase transition is exploited to enhance the desired cooling rate [2]. In this contribution we study turbulent flow in a heated plane channel in which the dispersed droplet phase is treated as a discrete set of point particles whose motion in the carrier gas is tracked. Momentum, heat and mass transfer between the gas and the liquid droplets is included. As a point of reference, we consider the flow of droplets of water in air, in which the presence of water vapor is accounted for. Together, air and water vapor will be referred to as the carrier gas and the liquid droplets are the dispersed phase.

The carrier phase is treated using a compressible formulation motivated by the fact that phase transitions are taken into consideration. This allows to incorporate and quantify the consequences of non-constant mass density of the carrier gas under a variety of thermal and turbulent conditions.

Previously, a numerical model was adopted using explicit time-stepping and second order accurate finite volume discretization [5]. The droplet equations are integrated in time with a four-stage Runge-Kutta method. The resulting accuracy in time is second order. However, the use of a realistic Mach number implies time steps that are too low to have affordable simulation times. Using low Mach numbers between 0.2 and 0.05 a clear convergence of the flow and droplet properties was found as function of the Mach number. However, the wish to perform efficient simulations with a realistic value of the Mach number which is an order of magnitude lower, motivates to formulate a new algorithm for the carrier gas, especially suited for low Mach numbers.

The structure of the abstract is the following: first, the mathematical model will be discussed, then the existing numerical model will be described and some results obtained using this model will be shown. Subsequently, the new algorithm will be introduced.

\section{MATHEMATICAL MODELING}

We consider a water-air system in a channel, bounded by two parallel horizontal plates. The domain has a size of $4 \pi H$ in the streamwise direction, which is denoted by $x$, and $2 \pi H$ in the spanwise direction, $z$, where $H$ is half the channel 
height, taken equal to $2 \mathrm{~cm}$ in this study. In addition, $y$ is the coordinate in the wall-normal direction. A constant heat flux $\dot{Q}$ is applied through the walls: this heat flux is positive through the top wall and negative trough the bottom wall. The flux at both walls is equal in size in order to conserve the total energy of the system. As a consequence, the gas temperature is higher at the top wall and lower at the bottom, and a temperature gradient develops across the channel. The considered system consists of two phases: the continuous and the dispersed. The continuous phase is composed of air and water vapor, the discrete dispersed phase is made up of water droplets. Initially, the droplets are randomly distributed over the total volume of the channel.

The difference between the existing time-explicit algorithm and the new low-Mach number formulation is in the treatment of the carrier phase. The implementation of the equations for the dispersed phase and the two-way coupling terms between the two phases is taken identical to the previously adopted numerical model [5]. Focusing on the carrier phase we treat this as a compressible Newtonian fluid. We impose conservation of mass, momentum, total energy density and water vapor. The equations can be written as [2] :

$$
\begin{array}{r}
\partial_{t} \rho+\partial_{j}\left(\rho u_{j}\right)=Q_{m} \\
\partial_{t}\left(\rho u_{i}\right)+\partial_{j}\left(\rho u_{i} u_{j}\right)=-\partial_{i} p+\partial_{j}\left(\mu(T) S_{i j}\right)+F_{i}+Q_{m o m, i} \\
\partial_{t} e+\partial_{j}\left((e+p) u_{j}\right)=-\partial_{j} q_{j}-\partial_{j}\left(u_{i} \mu(T) S_{i j}\right)+Q_{e} \\
\partial_{t}\left(\rho Y_{v}\right)+\partial_{j}\left(u_{j} \rho Y_{v}\right)=\partial_{j}\left(J_{v, j}\right)+Q_{m}
\end{array}
$$

This system is solved for mass density $\rho$, momentum density components $\rho u_{i}$, total energy density $e$ and vapor mass density $\rho Y_{v}$. The source terms $Q_{m}, Q_{m o m, i}, Q_{e}$ express the interaction between the phases. The term $F_{i}$ is an external force density. Applying periodic boundary conditions in the streamwise and spanwise directions, we have to make a choice for the calculation of this forcing term in order to maintain the flow in the channel. In the current study it is chosen in such a way that the total momentum in the streamwise direction is constant in time.

In equation (2) $S_{i j}$ is the compressible extension of the rate-of-strain tensor defined as $S_{i j}=\partial_{i} u_{j}+\partial_{j} u_{i}-\frac{2}{3} \Delta \delta_{i j}$ where $\Delta=\partial_{k} u_{k}$ denotes the divergence of the velocity. Here and elsewhere we adopt the summation convention implying summation over repeated indices. The dynamic viscosity of the carrier gas $\mu$ depends on temperature through Sutherland's law. In addition, $q_{j}$ in (3) denotes the components of the heat flux vector, which consists of heat transport by conduction and by diffusion of vapor. The vector $\mathbf{J}_{v}$ defines the diffusive mass flux of water vapor with respect to the mixture velocity. The pressure and temperature of the carrier phase are denoted by $p$ and $T$ and are connected by the ideal gas law for the two-component mixture. The total energy density of the gas $e$ is the sum of the kinetic energy density and the internal energy density, i.e., $e=e_{\text {int }}+e_{\text {kin }}$, where [4]

$$
\begin{aligned}
e_{k i n} & =\frac{1}{2} \sum_{j=1}^{3} \rho u_{j}^{2} \\
e_{i n t} & =\rho c_{v a} T\left(1-Y_{v}\right)+\rho c_{v v} T Y_{v}+\lambda Y_{v}
\end{aligned}
$$

Here $c_{v a}, c_{v v}$ are the values of the specific heats at constant volume of air and water vapor and $\lambda$ is the latent heat.

\section{SIMULATION WITH EXPLICIT-TIME STEPPING CODE}

An explicit time-integration method implies that the time step should be inversely proportional to the speed of sound in the carrier gas. This means that the upper boundary for the value of the time step is proportional to the value of the Mach number. Simulations with Mach number $\mathrm{Ma}=0.2,0.1$ and 0.05 were performed. In all three directions 128 grid cells are used, uniform in both periodic directions and clustered towards the walls. Figure 1 shows the droplet diameter history near the two walls at these Mach numbers. As can be seen droplets evaporate near the hot wall and water vapor condenses onto droplets near the cold wall. This figure also shows the mean droplet temperature as a function of the wall-normal coordinate. The results appear to converge for decreasing values of the Mach number.

The normalized droplet concentration near the cold wall is shown in figure 2. In order to calculate the droplet concentration the domain was divided into 40 equidistant bins in the wall-normal direction. The concentration is normalized by the uniform initial concentration. The migration of the droplets towards the walls is directly connected with the effect of turbophoresis. As is shown in [6] the tendency of this movement depends on the kinematics of the turbulent flow. Variations in the value of the Mach number do not significantly affect the kinematics of the turbulent 

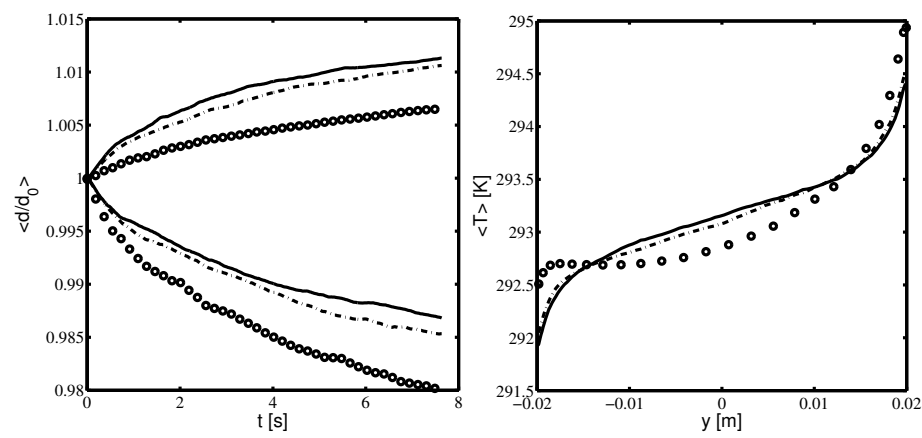

FIGURE 1. Left figure corresponds to droplet diameter history relative to initial diameter $\mathrm{d}_{0}$. The upper set of lines corresponds to the region near the cold wall, the bottom set of lines to the region near the hot wall. Circles: $\mathrm{Ma}=0.2$, dash-dotted: $\mathrm{Ma}=0.1$, solid: $\mathrm{Ma}=0.05$. The right figure corresponds to the averaged temperature, the average taken over the two periodic directions and over time $[2 \mathrm{~s} ; 8 \mathrm{~s}]$.
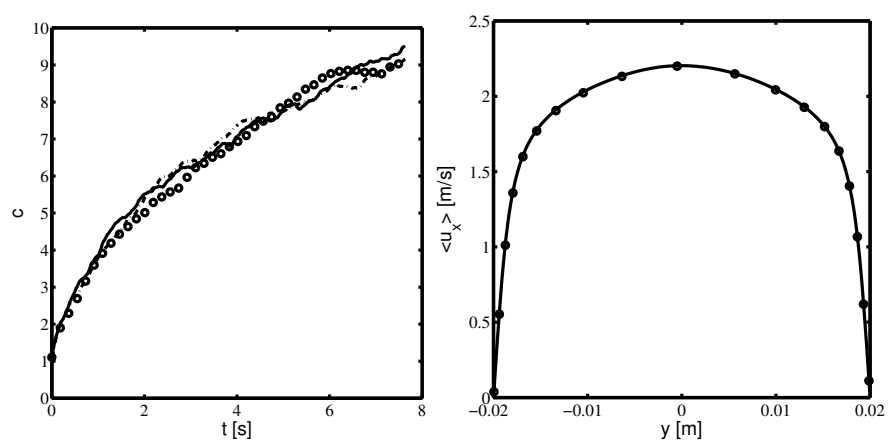

FIGURE 2. Left figure corresponds to droplet concentration history near the cold wall. Circles: $\mathrm{Ma}=0.2$, dash-dotted: $\mathrm{Ma}=0.1$, solid: $\mathrm{Ma}=0.05$. The right figure corresponds to the streamwise velocity of the carrier gas, averaged over the two periodic directions and over time $[2 \mathrm{~s} ; 8 \mathrm{~s}]$.

flow under the selected conditions with relatively modest water content in the system, as illustrated in figure 2 . This explains the rather high level of agreement between the results for the droplet concentration for different values of the Mach number.

In order to reach realistic, even lower, Mach number conditions a new algorithm is required which enables more efficient simulations at low Mach number. The physics of the problem must be taken into account: this implies extension of ideas for low-Mach time-stepping to situations where multiple phases are present. The contours of the new algorithm are discussed next.

\section{THE NEW LOW-MACH ALGORITHM}

The low Mach algorithm is based on ideas formulated in [3]. Instead of using the conservation equations (1)-(4), we use the three velocity components, the temperature and the vapor mass density as dependent variables. The pressure is considered to have two parts: thermodynamic, which is assumed constant in space, and hydrodynamic:

$$
p=p^{\text {therm }}(t)+p^{\text {hydr }}(t, \mathbf{x})
$$

Integration in time is performed with a two-stage Runge-Kutta method. In each stage first the temperature and vapor mass density are calculated with an explicit method:

$$
T^{(i)}=T^{(i-1)}+\beta(i) \Delta t F_{T}^{(i-1)}
$$




$$
\rho Y_{v}^{(i)}=\rho Y_{v}^{(i-1)}+\beta(i) \Delta t F_{\rho Y_{v}}^{(i-1)}
$$

where $i$ is the number of the stage, $\Delta t$ is the time step and $F_{T}, F_{\rho Y_{v}}$ denote the sum of the convective and viscous fluxes for the temperature and water vapor mass density equation, respectively, and $\beta(1)=1 / 2, \beta(2)=1$ as the weights of Runge-Kutta method. Next, the total mass density $\rho^{(i)}$ is obtained from the equation of state in the following way. It satisfies:

$$
\rho^{(i)}=\frac{p^{\text {therm },(i)}+T^{(i)} \rho Y_{v}^{(i)}\left(R_{\text {air }}-R_{\text {water }}\right)}{T^{(i)} R_{\text {air }}}
$$

where $R_{\text {air }}, R_{\text {water }}$ denote the specific gas constant of air and water, respectively. In addition, $p^{\text {therm, }(i)}$ is constant in space, but unknown at the new stage. Integration of (10) over the total volume of the channel gives a relation between the total mass $m^{(i)}$ of the carrier phase involving $p^{\text {therm, }(i)}$. Another expression for the total mass of the carrier phase in the channel can be found by integration of (1) over the total volume:

$$
m^{(i)}=m^{(i-1)}+\beta(i) \Delta t \int_{V} Q_{m} d V
$$

From these two expressions for $m^{(i)}$ it is now possible to calculate $p^{\text {therm, }(i)}$ and then $\rho^{(i)}$ follows from (10).

A pressure-correction procedure, similar to the one applied in incompressible flow, is followed to obtain the velocity at the new stage. In order to do that the assumption of $\mathrm{Dp} / \mathrm{Dt}=0$ is used, which is accurate at low Mach number [3]. On this basis we derive the following expression for the divergence of the velocity:

$$
\nabla \cdot \mathbf{u}=\frac{Q_{m}}{\rho}+\frac{1}{\rho \frac{\partial p^{\text {therm }}}{\partial \rho}}\left(\frac{\partial p^{\text {therm }}}{\partial T} \frac{D T}{D t}+\frac{\partial p^{\text {therm }}}{\partial Y_{v}} \frac{D Y_{v}}{D t}\right)
$$

First, the intermediate velocity of the carrier phase is computed, denoted by $\mathbf{u}^{(i, *)}$, using the convective and viscous fluxes evaluated at the previous stage and the lagged hydrodynamic pressure gradient. We define $S$ as the right-hand side of (12). Next, we solve a Poisson equation for the pressure:

$$
\nabla \cdot \frac{1}{\rho^{(i-1)}} \nabla p^{h y d r}=\frac{\nabla \cdot \mathbf{u}^{(i, *)}-S^{(i)}}{\Delta t}
$$

The value of $\mathbf{u}^{(i)}$ is then corrected:

$$
\mathbf{u}^{(i)}=\mathbf{u}^{(i, *)}-\Delta t \frac{1}{\rho^{(i-1)}} \nabla p^{h y d r}
$$

This finishes one stage of a time step where the velocity at the new stage is determined.

In the full paper we will show the application of the new algorithm to turbulent 3D flow and investigate the efficiency and accuracy of this method for different Mach numbers.

\section{ACKNOWLEDGMENTS}

This work is part of the research program DROP of the Foundation for Fundamental Research on Matter (FOM), which is part of the Netherlands Organisation for Scientific Research (NWO). This work was sponsored by the Stichting Nationale Computerfaciliteiten (National Computing Facilities Foundation, NCF) for the use of supercomputer facilities, with Financial support from the Nederlandse Organisatie voor Wetenschappelijk Onderzoek, NWO (project SH-061).

\section{REFERENCES}

1. S. Elghobashi, Appl. Sci. Res. 52, 309-329 (1994).

2. F. Mashayek, Int. J. Heat Mass Transfer 41, 2601-2617 (1997).

3. J.B. Bell, M.S. Day, C.A. Rendleman, S.E. Woosley and M.A. Zingale, J. Comput. Phys. 195, 677-694 (2004).

4. R.S. Miller and J.Bellan, J. Fluid. Mech. 384, 293-338 (1999).

5. A. Bukhvostova, E. Russo, J.G.M. Kuerten and B.J. Geurts, Proceedings of ETMM9, Thessaloniki, Greece.

6. J.G.M. Kuerten. Phys. Fluids 18, 025108 (2006). 